Journal of the Scholarship of Teaching and Learning, Vol. 19, No. 1, February 2019, pp. 41-52. doi: 10.14434/josotl.v19i1.26779

\title{
Curricular Learning Communities and Retention
}

\author{
Beth B. Kern \\ Indiana University South Bend \\ bkern@iusb.edu \\ Tabitha Kingsbury \\ Indiana University South Bend \\ takingsb@iusb.edu
}

\begin{abstract}
Learning communities have been a part of the bigher educational landscape since the 1980s. Despite their widespread use, research regarding their effectiveness with enhancing retention is sparse. This study describes a freshmen curricular learning community linking courses required for all business majors. Retention for students taking courses in a curricular learning community is compared to retention for students taking the same courses independent from a learning community. Analysis of the data indicates that students who participated in the learning community were twice as likely to persist to the following semester than the students in the baseline comparison group. The results provide evidence that purposeful structuring of courses in a curricular learning community with support imbedded to help students succeed is associated with improved retention.
\end{abstract}

Keywords: learning communities, retention, cohorts

The first year of college is instrumental for student learning and continuing student success (Barefoot et. al., 2005). The Association of American Colleges and Universities (AAC\&U) has identified ten high impact practices that have been demonstrated to be effective for a wide range of educational outcomes. Learning communities are one of these practices. By 2004, over 500 colleges and universities had implemented them (Smith, MacGregor, Matthews \& Gabelnick, 2004). Despite their widespread use, research regarding their effectiveness is "sparse and mixed" (DeAngelo, 2014). Their use in a nonresidential setting is even sparser. This study examines the use of a learning community for freshmen students at a regional Midwestern public university and its association with retention.

\section{Background}

\section{Description of Learning Communities}

Cox (2004) traces the early seeds of learning communities to Dewey (1933) and Meiklejohn (1932). Both independently advocated having cohorts of students taking common courses. Dewey's focus was on student-centered learning; Meiklejohn's motivation was to mitigate his concern regarding specialization in the disciplines leading to a fragmented learning experience for students. Over the years various efforts to form learning communities arose and dissipated. It was not until the 1980s that they gained traction (Cox, 2004) leading to their prevalence in universities today.

Learning communities can take many forms. Lenning and Ebbers (1999) take a broad view of learning communities describing four forms: curricular, classroom, targeted group learning, and residential communities. Curricular learning communities link two or more courses often serving the same group of students. A classroom learning community is focused on a sole classroom often using pedagogies such as cooperative learning or other group-based pedagogies to foster community within the classroom. Student learning communities focus on a targeted group of students such as honors students or underrepresented students. They can have either a social or academic supportive purpose. 
The final type of learning community is a residential learning community. They center on an academic interest building community via students living together.

This study focuses on a curricular learning community. Smith et. al. (2004) describe three forms of curricular learning communities. The first does not modify existing courses. At some large campuses, the existing courses may have very large enrollments. An additional course is added that may take the form of a freshmen interest group (FIG). FIGs typically have small enrollments (10 to 30 students). These interest groups can explore topics such as the transition to college, study groups, and shared academic interests. Another format that does not change existing courses is to add a course that is an integrative seminar which pulls together themes from the pre-existing courses.

A second form of curricular learning community explicitly links two or more courses together. The same set of students attends each of the courses that are linked. Although it is possible to have students in the linked classes who do not attend all the linked classes, Smith et. al. (2004) contend that the "broken cohorts" will tend to lead to a reduction in quality.

The final form of a curricular learning community is a team taught learning community. Tinto (2000) describes a similar format that he labels as "coordinated studies." This format is a single course that is the equivalent of two or more classes where the themes common to the courses are at the forefront of the larger course. The course tends to be highly interdisciplinary and integrated. At some universities, the larger themed course is sometimes disaggregated after the term's conclusion for the purposes of a transcript into the substituent smaller courses that were combined to form the integrated course.

\section{Potential Benefits from Curricular Learning Communities}

Despite learning communities' being a part of the higher educational landscape since the 1980s, the research regarding their effectiveness is sparse. Zhao and Kuh (2004) note that at that time of their research, few studies were readily available. Taylor et. al. (2003) were able to obtain 32 research studies that were primarily doctoral dissertations. They note a number of relationships between learning communities and positive learning outcomes. Nonetheless, they conclude that we need to "identify which aspects of learning communities are effective in which ways with which students" (p. 66).

Of all the potential benefits from learning communities, enhancing student engagement has been of particular interest (Zhao and Kuh, 2004; Pike, Kuh \& McCormick, 2011). Pike, Kuh and McCormick contend that since learning communities have a positive association with student engagement, and student engagement is positively associated with learning outcomes, then learning communities can be indirectly related to student learning (p. 314). Using a different data set, Rocconi (2011) echoes these studies by finding a positive relationship between learning community participation and student engagement along with a positive relationship between student engagement and self-reported educational gains.

While these studies have found an indirect positive relationship between learning community participation and educational gains or learning outcomes, Kilgo, Sheets \& Pascarella (2015) find no relationship between participating in learning communities and seven liberal arts learning outcomes. They caution, however, that these results should not be interpreted as learning communities' not having a benefit for students. Rather, they call for future research to "examine these practices more closely to explore how the effects of participation on students may vary according to facilitation and individual student characteristics" (p. 522).

Journal of the Scholarship of Teaching and Learning, Vol. 19, No. 1, February 2019. josotl.indiana.edu 


\section{Research Question}

This study assesses whether there is an association between participation in a curricular learning community and retention. Much of the literature regarding the effectiveness of learning communities has focused on residential learning communities (Inkelas, Daver, Vogt \& Leonard, 2007; Carrino \& Gerace, 2016) or learning communities broadly defined (Rocconi, 2011; DeAngelo, 2015; Zhao \& Kuh, 2004; Pike, Kuh \& McCormick, 2011). In reflecting on student retention, Tinto (2006) notes the importance of the classroom in student retention. In his view, if "involvement does not occur there, it is unlikely to occur elsewhere" (p. 4). Tinto (2012a) also urges institutions that wish to improve retention to focus on the classroom rather than "tinkering at the margins of institutional life" (p. 116). Despite the importance of the classroom for retention and other forms of student success, the literature regarding the effectiveness of curricular learning communities is scarce. This study focuses on curricular learning communities for required business courses at a campus that serves primarily commuter students. The primary research question is:

Is there a relationship between students' participating in a curricular learning community for required freshmen courses and their persistence to the following semester?

\section{Methodology}

\section{Description of the Study's Learning Communities}

The learning communities were formed at a regional public Masters granting university. The campus serves primarily commuter students. The learning communities link either two or three required freshmen courses for business and economics majors. The first semester learning community cohort links an introduction to business course to give the students a panoramic view of the different business functional areas, a career perspectives course to help them begin to process of choosing a career path, and microeconomics, a foundational discipline for business. The second semester freshmen cohort links a computer skills course with macroeconomics. The courses that often prove to be more challenging for the students have peer mentors imbedded in the courses. In addition, a block of time between courses is provided for tutoring as well as sessions dedicated to help with the transition to college. Free tutoring as well as success coaches were available to all freshmen during the time period of the study (fall 2016 through fall 2017), whether they took classes within or outside a learning community cohort.

Table 1 displays data regarding the sections in the learning community cohorts as well as those taught outside the learning community cohorts. A total of 22 sections of courses were taught in the learning community cohorts with 26 sections of the same courses taught outside of the learning community cohorts. A total of 12 different faculty taught students in the learning community cohorts with 16 different faculty teaching outside of the cohorts. Table 1 displays the number of fulltime and part-time faculty teaching in the learning community cohorts versus in the sections outside of the cohorts. Table 1 also displays the mean and median class sizes for the learning community cohort sections as well as those that were not in the learning community cohorts. The sections were similar in size with a greater variability in class size for the sections not in the cohorts. 
Kern and Kingsbury

Table 1. Description of Faculty and Section Size for Courses In and Out of Cohorts

Number of Fulltime versus Part-time Faculty Teaching Courses In and Out of Cohorts

By Number of Sections:

In Learning Community Cohorts Out of Cohorts

Fulltime Faculty

16

12

Part-time Faculty
6

Total Sections

14

22

By Unique Faculty:

In Learning Community Cohorts

Out of Cohorts

Fulltime Faculty

9

6

Part-time Faculty
3
10

Total Faculty

12

16

Section Sizes

\begin{tabular}{|c|c|c|c|c|c|c|}
\hline & $\begin{array}{l}\text { Number of } \\
\text { Sections }\end{array}$ & Mean & $\begin{array}{l}\text { Standard } \\
\text { Deviation }\end{array}$ & Quartile 1 & Median & Quartile 3 \\
\hline In Cohorts & 2239.6 & 3.9 & 40 & 41 & & 42 \\
\hline Out of Cohorts & 2638.6 & 12.6 & 30 & 40 & & 42 \\
\hline
\end{tabular}

Description of Sample

The analysis in this study is restricted to students who had freshman status as of the beginning of the semester. Freshman status is defined as having earned less than 30 hours of college credit. Most students taking courses in the freshmen business learning communities have freshmen status. A greater proportion of students who do not have freshman status take courses outside of the learning communities. The study restricts analysis to those students with freshmen status in order to have greater comparability in terms of the students' intellectual development between the students taking courses in learning community cohorts and those taking the same courses outside of the learning communities.

The study spans three semesters. A total of eight learning community cohorts occurred during this time. The study compares the retention of these students to that of freshmen taking the same courses during the same semesters outside of a learning community. A total of 606 student-semester observations were initially included in the sample. The study uses composite SAT scores (or converted ACT scores) as a control variable for academic ability. This variable was not available for 41 observations. Thus, the final sample includes 565 students. ${ }^{1}$

Table 2 displays student demographic characteristics along with measures of academic ability for the students taking courses within the learning community cohorts as well as those taking the courses outside of the learning community cohorts. The final sample has 293 student-semester observations for the learning community cohort group and 272 semester-student observations for students taking any of the same courses included in the learning community cohort during the same semester. Chi-square tests are performed to ascertain if students from differing backgrounds are disproportionately represented in the learning community cohorts. The only group that is

\footnotetext{
${ }^{1}$ If we had used high school GPA, a total of 42 students would have been eliminated from the sample. Journal of the Scholarship of Teaching and Learning, Vol. 19, No. 1, February 2019. josotl.indiana.edu
} 
disproportionately underrepresented in the learning communities are students from families with lower income levels. Table 2 also displays the average high school grade point averages (GPA) as well as composite SAT scores. Comparing the means fails to indicate a significant difference in either the average high school GPA or average SAT scores at conventional levels of significance. Data are obtained from a database at the university.

Table 2. Characteristics of Student-Semester Observations in Cohorts

\section{Panel A: Demographic Characteristics}

Student Characteristic

$\begin{array}{ccc}\text { In Cohort } & \text { Not in Cohort } & \text { p-value* } \\ \mathrm{n}(\%) & \mathrm{n}(\%) & \end{array}$

Gender

Female

Male

Race/Ethnicity

White

Black

Hispanic

Unavailable

$$
90(49.7 \%)
$$$$
203(52.9 \%)
$$

$196(51.6 \%)$

$25(43.1 \%)$

$33(48.5 \%)$

$39(66.1 \%)$

First Generation

Yes

No

Lower Parental Income

Yes

No
$118(50.4 \%)$

$175(52.9 \%)$

$28(34.1 \%)$

$239(49.5 \%)$

$293(51.9 \%)$
.486

$91(50.3 \%)$

$181(47.1 \%)$

.076

$184(48.4 \%)$

$33(56.9 \%)$

$35(51.5 \%)$

$20(33.9 \%)$

$116(49.6 \%)$

$156(47.1 \%)$

.567

$54(65.9 \%)$

$244(50.5 \%)$

$272(48.1 \%)$

Total

Panel B: Academic Ability Variables

Student Characteristic

High School GPA

Composite SAT**

$$
\text { Mean (n) }
$$

$3.06(282)$

1050 (293)
Mean (n)

3.00 (282)

$1031(272)$

*p-values for demographic variables are based on Pearson Chi-Square tests.

$\mathrm{p}$-values for academic ability variables are based on t-tests.

**Composite SAT includes conversions of ACT scores to an SAT score as well as conversions for students' taking differing versions of the SAT. 


\section{Data Analysis Model}

A learning community cohort may attract students with greater academic ability (Zhao \& Kuh, 2004). Similar to Zhao and Kuh, we use a student's entering composite SAT (or converted ACT) score as a measure of academic ability. We use several student demographic characteristics as additional control variables. We use indicator variables for gender, ethnicity and first generation status (Zhao \& Kuh, 2004; Inkelas, Daver, Vogt \& Leonard, 2007; Pike, Kuh and McCormick, 2011; Hill \& Woodward, 2013). We also use a proxy for parental income, $21^{\text {st }}$ Century Awardee. These students are granted a full tuition scholarship based on family income levels falling below levels dictated by size of family. To continue to receive the scholarship, the students must make satisfactory academic progress while in college. The dependent variable is dichotomous indicating that the student returned to the university in the subsequent semester or did not. The model used to assess our primary research question is:

$$
\begin{aligned}
& \text { RETAIN }_{i t}=\beta_{0}+\beta_{1}{ }^{*} \text { COHORT }_{i t}+\beta_{2}{ }^{*} S A T_{i t}+\beta_{3}{ }^{*} \text { GENDER }_{i t}+\beta_{4-6} \sum \text { ETHNICITY }_{i t} \\
& +\beta_{7} \text { FIRSTGEN } \\
& \text { EIt }
\end{aligned}
$$

A second model adds an indicator variable for the semester in which the courses were taught in order to control for factors that may influence a student's decision to attend the university in the following semester.

$$
\begin{aligned}
& \text { RETAIN }_{i t}=\beta_{0}+\beta_{1}{ }^{*} \text { COHORT }_{i t}+\beta_{2}{ }^{*} S A T_{i t}+\beta_{3}{ }^{*} \text { GENDER }_{i t}+\beta_{4-6} \sum \text { ETHNICITY }_{i t} \\
& +\beta_{7} \text { FIRSTGEN } \\
& \text { EIt }
\end{aligned}
$$

Since the dependent variable, RETAIN, is dichotomous, we use logistic regression to estimate the parameters and standard errors.

\section{Results}

Table 3 displays the percentage of students who were retained in the learning community cohorts versus that for the students who took the same classes outside of a learning community. The learning community students' retention rate is $86.3 \%$ compared to that of the students taking the same classes outside of a learning community cohort of $75 \%$. A Chi-square test of independence indicates that these proportions are statistically significantly different from each other at conventional levels.

Table 3. Retention by Learning Community Participation

Number of Students Who Were Retained by Learning Community Participation

Not

$\begin{array}{ccc}\text { Retained } & \text { Retained } & \text { Total } \\ \mathrm{n}(\%) & \mathrm{n}(\%) & \end{array}$

In Learning Community Cohort

Not in Learning Community Cohort

Total

Pearson Chi-Square statistic: $11.73(\mathrm{p}<.001)$

$\begin{array}{lrr}253(86.3 \%) & 40(13.7 \%) & 293 \\ 204(75.0 \%) & 68(25.0 \%) & 272 \\ & & \\ 457(80.9 \%) & 108(19.1 \%) & 565\end{array}$

Results from Binary Logistic Regression Model

Table 4 displays the results from the binary logistic regression model. The model's Chi-square statistic is significant at conventional levels providing evidence that the model fits the data well. The Hosmer and Lemeshow test is not significant. For this test a lack of significance is an indicator of a model

Journal of the Scholarship of Teaching and Learning, Vol. 19, No. 1, February 2019. josotl.indiana.edu 
Kern and Kingsbury

with a good fit (Homer, Lemeshow and Sturdivant, 2013). The model predicts whether a student is retained or not $80.9 \%$ of the time.

\section{Table 4. Likelihood of Retention from Participation in a Learning Community Cohort}

Panel A: Model without Semester Dummy Variable

Dependent Variable: Retain ( $0=$ Not Retained $)$

\begin{tabular}{|c|c|c|c|c|c|c|}
\hline Variable & $\beta$ & $\mathrm{SE}(\beta)$ & Wald & $\begin{array}{l}\text { Odds } \\
\text { Ratio }\end{array}$ & $\begin{array}{c}95 \% \text { CI } \\
\text { Odds Ratio }\end{array}$ & p-value \\
\hline Learning Community Cohort $(0=\mathrm{No})$ & .702 & .225 & 9.693 & 2.017 & $1.297-3.137$ & .002 \\
\hline SAT Score & .002 & .001 & 4.914 & 1.002 & $1.000-1.004$ & .027 \\
\hline Gender $(0=$ Male $)$ & .366 & .248 & 2.189 & 1.443 & $.888-2.344$ & .139 \\
\hline Ethnicity $(0=$ White $)$ & & & .562 & & & .905 \\
\hline Black & -.060 & .360 & .028 & .942 & $.465-1.908$ & .868 \\
\hline Hispanic & .134 & .355 & .143 & 1.144 & $.570-2.293$ & .706 \\
\hline Unknown & -.202 & .364 & .308 & .817 & $.401-1.667$ & .579 \\
\hline First Generation $(0=\mathrm{No})$ & .289 & .230 & 1.569 & 1.335 & $.850-2.096$ & .210 \\
\hline Lower Parental Income $(0=\mathrm{No})$ & -.347 & .349 & .987 & .707 & $.356-1.402$ & .320 \\
\hline Intercept & -1.005 & 1.049 & .918 & .338 & & .366 \\
\hline \multicolumn{7}{|l|}{ Model Statistics } \\
\hline & \multicolumn{3}{|c|}{-2 Log Likelihood: 529.751} \\
\hline \multicolumn{3}{|l|}{ Cox \& Snell Psuedo-R ${ }^{2}: .037$} & \multicolumn{4}{|c|}{ Nagelkerke Pseudo--R ${ }^{2}: .060$} \\
\hline
\end{tabular}

Panel B: Model with Semester Dummy Variable

Dependent Variable: Retain ( $0=$ Not Retained)

\begin{tabular}{|c|c|c|c|c|c|c|}
\hline Variable & $\beta$ & $\mathrm{SE}(\beta)$ & Wald & $\begin{array}{l}\text { Odds } \\
\text { Ratio }\end{array}$ & $\begin{array}{c}95 \% \text { CI } \\
\text { Odds Ratio }\end{array}$ & p-value \\
\hline Learning Community Cohort $(0=\mathrm{No})$ & .630 & .228 & 7.616 & 1.877 & $1.200-2.936$ & .006 \\
\hline SAT Score & .002 & .001 & 5.682 & 1.002 & $1.000-1.004$ & .017 \\
\hline Gender ( $0=$ Male $)$ & .368 & .250 & 2.170 & 1.445 & $.885-2.359$ & .141 \\
\hline Ethnicity $(0=$ White $)$ & & & .627 & & & .890 \\
\hline Black & -.079 & .362 & .047 & .924 & $.454-1.880$ & .828 \\
\hline Hispanic & .152 & .357 & .182 & 1.164 & $.579-2.342$ & .670 \\
\hline Unknown & -.201 & 367 & .302 & .818 & $.398-1.678$ & .583 \\
\hline First Generation $(0=\mathrm{No})$ & .312 & .233 & 1.794 & 1.366 & $.865-2.157$ & .180 \\
\hline Parental income $(0=\mathrm{No})$ & -.400 & .352 & 1.295 & .670 & $.336-1.335$ & .255 \\
\hline Semester $(0=$ Fall 2016) & & & 5.650 & & & .059 \\
\hline Spring 2017 & .095 & .267 & .126 & 1.099 & $.651-1.856$ & .723 \\
\hline Fall 2017 & -.525 & .272 & 3.723 & .592 & $.347-1.008$ & .054 \\
\hline Intercept & -1.013 & 1.069 & .899 & .363 & & .343 \\
\hline
\end{tabular}

Chi-square: $27.047(\mathrm{p}=.003)$

Cox \& Snell Psuedo-R²: .047

-2 Log Likelihood: 524.265

Hosmer and Lemeshow Test: Chi-square: $10.706(\mathrm{p}=.219)$

The results from the model with no semester dummy variable are displayed in Panel A of Table 4. In terms of the control variables, only the coefficient for a student's SAT score is statistically Journal of the Scholarship of Teaching and Learning, Vol. 19, No. 1, February 2019. josotl.indiana.edu 
significant at conventional levels. The results for the gender, first generation, and lower parental income variables are congruent with that found in DeAngelo (2014) when she examined students' intent to persist to the sophomore year.

The coefficient for participation in a learning community cohort is significant at conventional levels $(\mathrm{p}=.002)$. After controlling for academic ability, gender, ethnicity, first generation status, and a measure of parental income, there is evidence of a positive relationship between taking courses in a curricular learning community and returning to the university in the subsequent semester. The odds ratio for the learning community indicator variable is 2.017 . This indicates the baseline student ${ }^{2}$ is 2.017 times more likely to persist to the next semester if he/she participates in a curricular learning community than if he/she took courses outside the learning community.

Figure 1 displays a graph of the model's mean predicted probability of a student's persisting to the following semester versus composite SAT score. For students across the entire range of SAT scores, the predicted probability is higher if students participated in a curricular learning community cohort than if they took the same courses outside the learning community cohort.

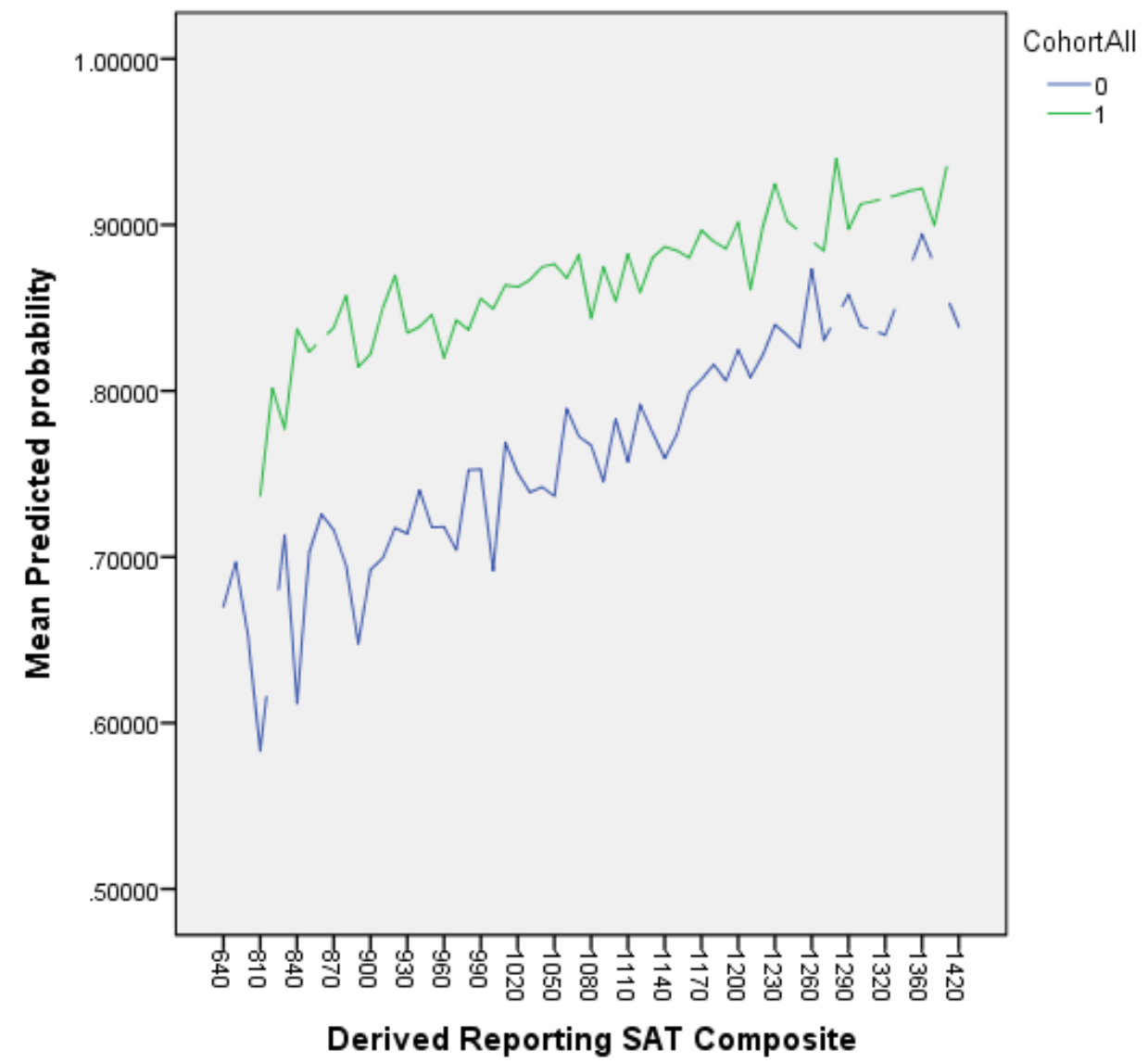

Figure 1. Mean predicted probability of retention versus a student's SAT score by learning community cohort status.

Additional analyses (not reported) were performed to assess the sensitivity of the model to differing specifications. Interaction terms between each of the control variables and the learning

\footnotetext{
${ }^{2}$ The baseline student with zeros for the indicator variables is male, white, not first generation, not first generation and does not have low family income.
}

Journal of the Scholarship of Teaching and Learning, Vol. 19, No. 1, February 2019. 
community cohort indicator were added. None of the interactions proved to be statistically significant. High school GPA was substituted as a measure of academic ability. The results for the models were not qualitatively different from the results reported using SAT scores as an indicator of academic ability.

Panel B of Table 4 displays the results from adding dummy variables as a semester time indicator to control for other factors that may be related to the particular semester in which the courses occurred. For example, the decision to return to college from fall to spring may be different than that from spring to fall. None of the semester indicator variables are significant at conventional levels, and the addition of these indicator variables does not materially change the statistical significance of the variables in the model without a semester indicator.

\section{Limitations}

This study was conducted at a regional public university primarily serving commuter students. The results may not extend to other campuses with different learning environments serving students who differ from the students included in this study's sample. For example, the opportunity for commuter students to participate in a curricular learning community may have a stronger association with retention than one would observe at a campus with primarily residential students who have greater opportunities to engage with faculty and their peers. Although the campus is typical of many regional campuses, a sample drawn from another university may produce different results.

Participation in the learning community cohorts was voluntary. Although control variables were used to attempt to control for this issue, there may be variables correlated with the choice to participate in a learning community and a student's persisting to the following semester that were not measured. Although this is a significant limitation, analyses of the association "among significant constructs have an important role to play in educational research" (Pike, Kuh \& McCormick, 2011).

\section{Discussion}

Research regarding learning communities is not as well developed as research on several other high impact practices (i.e. first year seminars). The results of this study have important implications for those who wish to improve retention via the structure of how they organize courses in their curriculum. The results find evidence that students who take courses in a curricular learning community are twice as likely to persist as the reference group of students who took the same classes without having them linked in a learning community cohort. This finding holds across all levels of academic ability as measure by SAT score.

In reflecting about learning communities and student engagement, Pike, Kuh and McCormick (2011, p. 317) indicate that "in order to maximize the potentially positive effects of learning communities, intentional, contextualized design and implementation efforts are needed." This study provides evidence of a learning community structured in a manner to enhance retention of primarily commuter freshmen students. The learning community's structure incorporates the elements of Tinto's (2012a) model for student success.

Tinto's model has four attributes that fall under an institution's control: high expectations, support to meet expectations, assessment and feedback to faculty and staff, and involvement (engagement). This study's learning community cohorts can facilitate accomplishing the attributes of Tinto's model more easily than one could with independent courses. In terms of high expectations, challenging courses are purposely selected to be part of the learning community cohorts. In addition, junior and senior students who had achieved notable accomplishments as undergraduates visit the

Journal of the Scholarship of Teaching and Learning, Vol. 19, No. 1, February 2019. josotl.indiana.edu 
cohorts during the first week of the semester to discuss the opportunities available to these students in order to begin to set high expectations.

In terms of support, the students in the learning community cohorts had peer mentors for each of the most challenging classes with special sessions during the block of time set aside in the middle of the cohort for exam review, extra problem sessions, tips on study skills and sessions focused on the transition to college. While all the required freshmen business courses have free tutoring available, the independent classes did not have the common open time to bring this extra support to the students. Instead, the students needed to go to the support.

With regard to assessment and feedback, there is an early warning system to alert advisors of students having difficulty in any course. The learning community cohort had an imbedded advisor who reached out to students having academic and nonacademic challenges. While advisors were available to students who enrolled in courses outside of the learning community, these advisors were not imbedded in the courses thereby making communication more challenging.

Finally, in terms of engagement, the learning community students attended multiple classes together scheduled consecutively. All the learning community cohorts had bocks of time intentionally scheduled to facilitate not only support but also additional opportunities for the students to engage with each other, their faculty and campus support staff. Thus, the structure created the time and opportunities for engagement even for commuter students who may arrive just before classes and leave shortly thereafter. The opportunities for engagement for the independent classes were available, but their availability either just before or after class would have been incidental rather than purposeful.

It is unknown which of the elements of the learning community structure are most important for student success. This is fertile ground for future research. It very well may be difficult to disentangle the efficacy of the relevant components. As Tinto (2012b, p. 260) indicates, student success is most likely when all four of his model's attributes "are linked in such a way that each is supportive of the others." The learning community cohorts that are the subject of this study provide a structure that facilitates student success with evidence of an association of enhanced retention for the students that participate in them.

\section{Concluding Remarks}

Tinto (2000, p. 6) observes that 'learning communities do not represent a 'magic bullet' to student learning." Despite their prevalence in higher education, little research is available to assist faculty and administrators with structuring learning communities to maximize potential positive student outcomes and minimize poor ones. This study provides a description of a curricular learning community structure and evidence of its effectiveness. But, much more work remains to answer Taylor et. al.'s (2003, p. 66) call to "identify which aspects of learning communities are effective in which ways with which students."

\section{References}

Barefoot, B., Gardner, J., Cutright, M., Morris, L, Schroeder, C., Siegel, M. \& Swing, R. (2005). Achieving and Sustaining Institutional Excellence for the First Year of College. San Francisco: JosseyBass.

Carrino, S. and Gerace, W. (2016). Why STEM learning communities work: The development of psychosocial learning factors through social interaction. Learning Communities Research and Practice 4 (1): Article 3.

Journal of the Scholarship of Teaching and Learning, Vol. 19, No. 1, February 2019. josotl.indiana.edu 
Kern and Kingsbury

Cox, M.D. (2004). Introduction to faculty learning communities. In M.C. Cox \& L. Richlin (Eds.), Building Faculty Learning Communities, New Directions for Teaching and Learning 97 (Spring).

DeAngelo, L. (2014). Programs and practices that retain students from the first to second year: Results from a national study. New Directions for Institutional Research 160 DOI:

10.1002/ir.20061

Dewey, J. (1933). How We Think. Lexington, MA: Heath.

Hill, W. and Woodward, L. (2013). Examining the impact of learning communities have on college of education students on an urban campus. Journal of College Student Development 54 (6): 643648.

Hosmer, D., Lemeshow, S. and Sturdivant, R. (2013). Applied Logistic Regression (3 ${ }^{\text {rd }}$ ed.). John Wiley and Sons.

Inkelas, K., Daver, Z., Vogt, K. \& Leonard, J. (2007). Living-learning programs and first-generation college students' academic and social transition to college. Research in Higher Education 48 (4): 403-433.

Kilgo, C., Sheets, J. \& Pascarella, E. (2015). The link between high-impact practices and student learning: Some longitudinal evidence. Higher Education 69: 509-525.

Lenning, O., \& Ebbers, L. (1999). The powerful potential of learning communities: Improving education for the future. ASHE-ERIC Higher Education Report 26 (6).

Meiklejohn, A. (1932). The Experimental College. New York: Harper Collins.

Pike, G., Kuh, G. \& McCormick, A. (2011). An investigation of contingent relationships between learning community participation and student engagement. Research in Higher Education 52: 300-322.

Rocconi, L. (2011). The impact of learning communities on first year students' growth and development in college. Research in Higher Education 52: 178-193.

Smith, B.L, Macgregor, J., Matthews, R.S. \& Gablenick, F. (2004). Learning Communities: Reforming Undergraduate Education. San Francisco: Josey Bass.

Taylor, K. with Moore, W., MacGregor, J. and Lindblad, J. (2003). Learning Community Research and Assessment: What We Know Now. National Learning Communities Project Monograph Series. Olympia, WA: The Evergreen State College, Washington Center for Improving the Quality of Undergraduate Education.

Tinto, V. (2000). Learning better together: The impact of learning communities on student success. Journal of Institutional Research 9 (1): 48-53.

Tinto, V. (2006). Research and practice of student retention: What next? Journal of College Student Retention 8 (1): 1-19.

Journal of the Scholarship of Teaching and Learning, Vol. 19, No. 1, February 2019.

josotl.indiana.edu 
Kern and Kingsbury

Tinto, V. (2012a). Completing College: Rethinking Institutional Action. Chicago, IL: University of Chicago Press.

Tinto, V. (2012b). Moving from theory to action: A model of institutional action for student success. In A. Seidman (Ed.), College Student Retention: Formula for Student Success ( $2^{\text {nd }}$ ed.). Lanham, MD: Rowman and Littlefield Publishers.

Zhao, C. \& Kuh, G. (2004). Learning communities and student engagement. Research in Higher Education 45: 115-138.

Journal of the Scholarship of Teaching and Learning, Vol. 19, No. 1, February 2019. josotl.indiana.edu 